$\xi=-1$

\title{
Hybrid Converter to Supply DC and AC Loads Using Tapped Boost Topology
}

\author{
Goutham Menon $^{1}$, Mahesh Ratheesh ${ }^{2}$, Gopikrishna S Menon ${ }^{3}$, Gautham ${ }^{4}$ And P. Kanakasabapathy ${ }^{5}$ \\ ${ }^{1}$ Department Of Electrical And Electronics Engineering, Amrita Vishwa Vidyapeetham, Amritapuri, India \\ ${ }^{2}$ Department Of Electrical And Electronics Engineering, Amrita Vishwa Vidyapeetham, Amritapuri, India \\ ${ }^{3}$ Department Of Electrical And Electronics Engineering, Amrita Vishwa Vidyapeetham, Amritapuri, India \\ ${ }^{4}$ Department Of Electrical And Electronics Engineering, Amrita Vishwa Vidyapeetham, Amritapuri, India \\ ${ }^{5}$ Department Of Electrical And Electronics Engineering, Amrita Vishwa Vidyapeetham, Amritapuri, India \\ E-Mail:(' goutham.Menon2996, ${ }^{2}$ mahesh.13296, ${ }^{3}$ harigopi1,${ }^{4}$ Gauthams58)@Gmail.Com, ${ }^{5}$ sabapathy@Am.Amrita.Edu
}

\begin{abstract}
Advancements in power electronic systems has brought forth the modernization of residential power systems exponentially. The interfacing of AC and DC loads with various kinds of resources of energy has been achieved with the help of modern nanogrid architectures. This paper brings into depiction a Tapped Boost derived hybrid converter that can be used to meet the demands of both AC and DC loads having a solitary DC input. A voltage source inverter (VSI) bridge network is used instead of the single switch of a Tapped Boost converter. The VSI bridge has shoot-through protection in the inverter stage increasing its importance for smart power systems. The Tapped Boost derived converter also borrows the advantages provided by the Tapped Boost converter. The paper covers topics like the operation, steady-state analysis and operating modes of the proposed Tapped Boost-DHC. The output and input characteristics has also been tested and verified through simulation

Keywords: Tapped Boost - derived hybrid converter (Tapped Boost-DHC); nanogrids; sine pulse width modulation; switching cell
\end{abstract}

\section{Introduction}

As the population of earth grows by leaps and bounds, so too does its need for energy on a daily basis increase exponentially. This need has brought to light the crucial importance of incorporating renewable sources of energy into the conventional grid system. The depletion of our current basic sources of energy has given incentive for brilliant minds in the energy field to bring forth new and better technologies, initiatives and technologies which aid in the better implementation of resources of renewable energy [1]. The implementation of power electronic converters has eased this seemingly up-hill task. Renewable energy resources, its use and implementation techniques has gained attention mainly because of the deteriorating ecological health of the earth, regulation problems of the power sector, scientific and experimental advancements related to the field, etc $[9,11,12]$.

When local loads are combined with renewable energy resources, they form an independent power system generally known as nanogrids. Nanogrid is actually a smaller unit of Microgrid, generally useful in residential power applications. Nanogrids use both non-renewable and renewable sources to provide the required supply to load, thereby paving the path for the utilization of renewable energy $[1,10]$.

As the advent of smart grids has shown considerable promise in the energy sector, it has also stemmed the increasing incorporation of nanogrid architectures into smart residential electrical power systems $[2,3,4]$. It is in these residential power systems that the presence of AC and DC loads interfaced with renewable and nonrenewable energy sources is seen. This is where power electronics and specially, hybrid converter play an important part. Hybrid converters are called so as it can provide for both $\mathrm{AC}$ and $\mathrm{DC}$ loads i.e. it can perform both DC-DC and DC-AC conversions in a single module $[13,14]$. This paper is based on a similar hybrid converter topology.

The hybrid converter proposed is named Tapped Boost derived hybrid converter (Tapped Boost-DHC) as it is derived from a conventional Tapped Boost topology. More about Tapped BoostDHC and its operation is discussed in Section II.

\section{Tapped Boost-DHC and its Operation.}

When the boost topology is isolated by the implementation of a transformer in the form of a storage inductor, it is known as the Tapped Boost topology as shown in Fig 1. The transformer is not only for the provision of isolation of the boost topology but also to aid in the control of the output voltage by varying the turns ratio $[2,5,6]$. In the proposed converter, the switch of a Tapped Boost converter has been changed into a VSI bridge network, thereby being able to provide DC to AC conversion [15]. The tapped boost topology can boost output values more than the conventional boost converter, this is mainly because of the mutual inductance formed due to central tapping of the inductor. This can ensure continuous AC as well as DC outputs from the converter without any break or irregularities. This function of the Tapped BoostDHC is highly useful when it comes solar panel applications. With this converter input from the solar panel can be directly converted to AC voltage and supplies to AC mains and the DC output voltage can be used to charge batteries. 


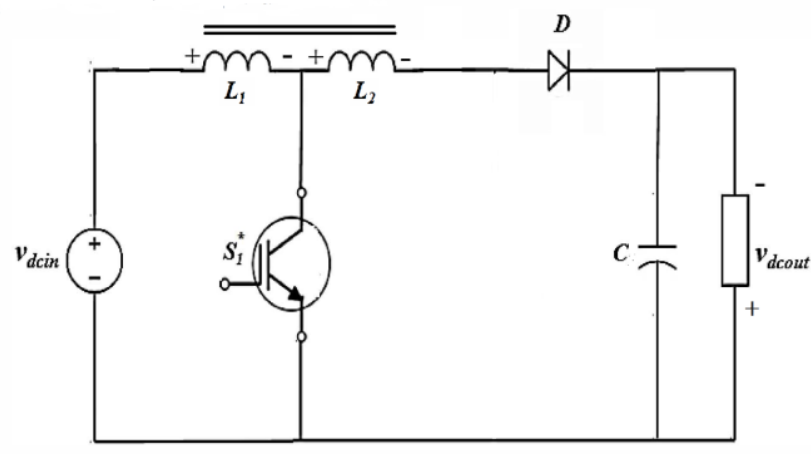

Fig 1: Conventional Tapped Boost Converter

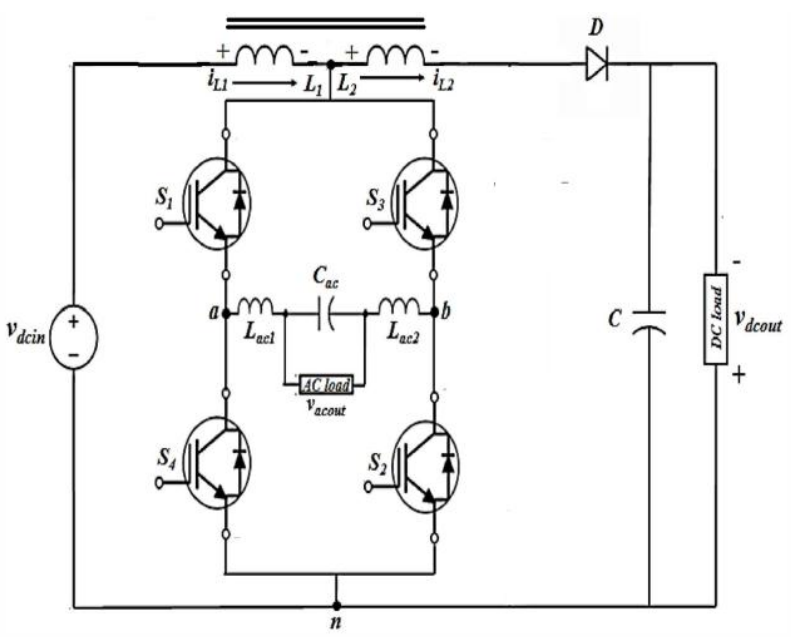

Fig 2: Tapped Boost-DHC

The VSI Bridge used in this converter consists of 4 switches ( $\mathrm{S} 1-$ S4) which are used to make the 3 modes for the necessary operation. The switches used can be either MOSFETs or IGBTs which have diodes alongside them. The buck and boost operations can be attained by switching these switches in unique patterns [16]. As mentioned before only 3 such modes are necessary. Switching on two switches along the same leg (S1-S4 or S2-S3) it is similar to the switching on of the singular switch in the basic Tapped Boost converter circuit. The pulse width modulation (PWM) technique is done to obtain the DC-output within the required limits. The voltage between the node holding the switches (vsn) is the inverter input [17]. Voltage is switched by the inverter between the instantaneous voltage across the capacitor (Cac) and zero. This negligibly small change from the average value below steady state is kept constant [19].

\subsection{Different Modes of Operation}

The operation of the Tapped Boost-DHC is defined in 3 different modes -Mode 1, Mode 2, and Mode 3.

Mode 1 (shoot-through interval): By switching on one side of the H-bridge configuration (S1-S4 or S2-S3) we form a straight path which is similar to the switching on of the circuit in the basic Tapped Boost converter. It is by controlling the interval that we can get the duty ratio (Dst) for achieving the boost operation of the DC output. The diode becomes reverse biased during which in the VSI network H- bridge switches, the inverter current circulates as shown in Fig 3. It is during this mode of operation when boost operation takes place as the switching combination makes the VSI bridge function as a closed switch entirely.

Mode 2 (power interval): During this mode (shown in Fig 4), alternate switches in upper and lower pairs are switched on, so as to provide a flow through the central circuit, in this case the AC load.
It can be S1 and S2 together or S3 and S4 together. It is during this mode invertion the DC input current takes place. The $\mathrm{C}$ current flows through the VSI bridge. Filter inductors and capacitors are used for the smoothening of the AC output wave.

Mode 3 (Null or Zero interval): In Mode 3 (shown in Fig 5) the inverter current circulates between $\mathrm{S} 1$ and $\mathrm{S} 3$ or between $\mathrm{S} 4$ and S2. During this mode the entire VSI bridge will function like an open switch so that the DC input current will flow directly to the other side. Since there is circulation taking place inside the VSI bridge network there will be inversion of DC current.

The 3 modes are selected in such a way that the required inverter operation and thee required convert operation occurs. By selecting an ideal control strategy for the switches of the bridge configuration, we are able to attain the DC output expected. As is usual for a typical tapped boost converter, adjusting Duty (Dst) gives a boost operation. For AC load selecting an apt PWM strategy should get the desired output. The control strategy should manage both needs simultaneously and hence selecting a control strategy which encompasses both is of utmost importance. Also the 4 switches selected should take care of the voltage and current needs of the same.

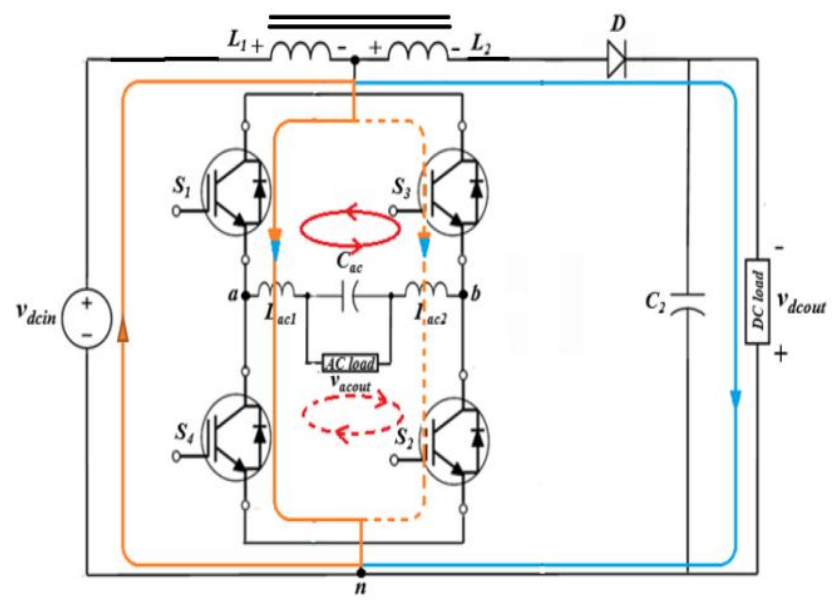

legend: $=$ input current

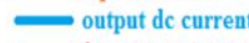

- inverter current

Fig 3: Mode 1 Operation

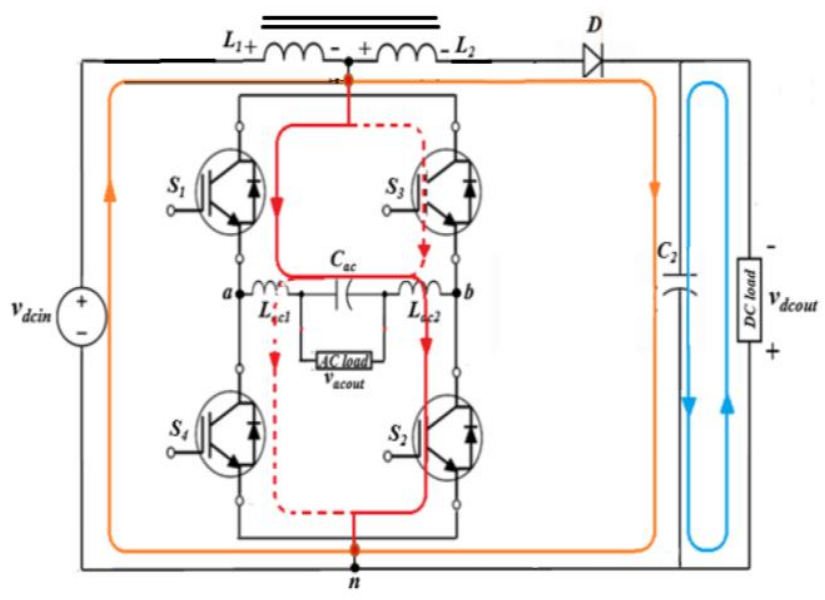

Fig 4: Mode 2 Operation 


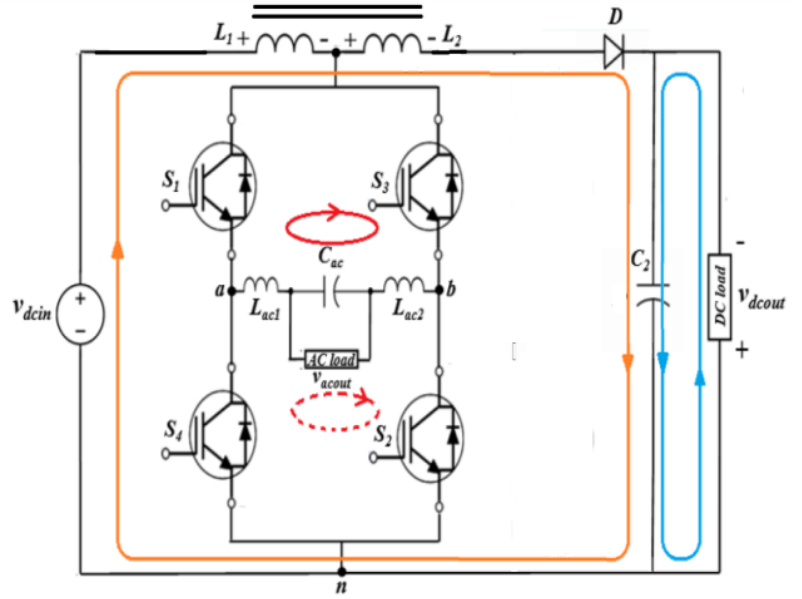

Fig 5: Mode 3 Operation

\subsection{Steady State Analysis}

The converter implements Mode 1 working by implementing a scenario where one side of the VSI bridge is closed and hence the working resembles a conventional tapped boost converter. Hence its acts like a closed switch. During this phase boosting of the input DC voltage happens. There will be current induced in the secondary side of the mutual inductance and that will charge the capacitor.

In Mode 2 and Mode 3 is where inversion of the DC current takes place because current will flow through the VSI Bridge.

Vdcin is the DC source voltage, Vdcout is the output DC voltage and Vacout is the AC voltage produced at the VSI bridge. During the time DTs, the equation for voltage across the inductors when $\mathrm{S} 1 \& \mathrm{~S} 4$ or $\mathrm{S} 2 \& \mathrm{~S} 3$ are on can be written as

$\mathrm{VL}_{1}=\mathrm{Vdcin} \quad$ for $(\mathrm{D}-\mathrm{d}) \mathrm{Ts}$ second

$\mathrm{VL}_{2}=\mathrm{nVdcin}$

for (D-d)Ts second

When $\mathrm{S} 2$ \& $\mathrm{S} 4$ or $\mathrm{S} 1 \& \mathrm{~S} 3$ are on,

$\begin{array}{ll}\mathrm{VL}_{1}=\mathrm{Vd} \pm \text { Vacout } & \text { for dTs seconds } \\ \mathrm{VL}_{2}=\mathrm{n}(\mathrm{Vdcin} \pm \mathrm{V} \text { acout }) & \text { for dTs seconds }\end{array}$

During (1-D)Ts time,

$\mathrm{VL}_{1}=[\mathrm{N} 1 /(\mathrm{N} 1+\mathrm{N} 2)][\mathrm{Vdcout}-\mathrm{Vdcin}]$

$\mathrm{VL}_{2}=[\mathrm{N} 2 /(\mathrm{N} 1+\mathrm{N} 2)][\mathrm{Vdcout}-\mathrm{Vdcin}]$

Applying volt second balance of L1,

Vdcin $(D-d) T s+($ Vdcin \pm Vacout $) d T s=[N 1 /(N 1+N 2)][$ Vdcout Vdcin][1-D]Ts

DVdcin \pm dVacout $=(1-\mathrm{D})($ Vdcout - Vdcin $)(1 /(1+n))$

DVdcin \pm dVacout + nDVdcin \pm ndVacout $=$ Vdcout - Vdcin + DVdcin - DVdcout $(1+\mathrm{nD})$

Vdcin $\pm d(1+n)$ Vacout $=$ Vdcout $(1-D) d(1+n)$ Vacout
During Boosting,

$\begin{array}{ll}\text { Vdcout }= & \frac{(1+\mathrm{nD})}{(1-\mathrm{D})} \mathrm{Vdcin}+\frac{(1+\mathrm{n})}{(1-\mathrm{D})} \mathrm{dVacout} \\ \text { During } & \text { Inversion, }\end{array}$

Vdcout $=\frac{(1+\mathrm{nD})}{(1-\mathrm{D})} \mathrm{Vdcin}-\frac{(1+\mathrm{n})}{(1-\mathrm{D})} \mathrm{dVacout}$

\subsection{Controlling AC and DC Outputs}

$\mathrm{AC}$ and DC output can be controlled by changing the values of Vcarrier $(t)$ and $V s t(t)$ which is the reference signal used in the PWM technique. By changing the frequency of the sine wave $\mathrm{Vm}(\mathrm{t})$ we can set the output AC frequency. Amplitude of the carrier triangular wave and the shoot through signal value is adjusted to change the AC and DC output values. The Amplitude of Vcarrier(t) must be the highest always. $\mathrm{Vm}(\mathrm{t})$ should be lower than Vst $(t)$ and $V$ carrier $(t)$. The detailed explanation of these signals and its working is provided in the next section.

\section{Control Methodology}

Sinusoidal pulse width modulation method is used for controlling the switching. In this method a sinusoidal signal is compared with a triangular wave of high amplitude to generate the required pulse. The principle of the control strategy for the proposed hybrid tapped boost converter is that M2 should be receiving a positive voltage at the VSI input. When Vm has non-zero values the inverter output should be modulated accordingly. The boosting operation of the converter takes place when there is no current flowing through the VSI Bridge that is Vab is 0. The output voltage of the inverter has 3 different values. Because of this, unipolar SinePWM modulation strategy is used for the purpose of switching. This provides for the 3 different voltage levels for the output [18]. Reference signals $\mathrm{Vst}(\mathrm{t})$ and $\mathrm{Vm}(\mathrm{t})$ are compared with a triangular signal Vcarrier(t) of high frequency. Vst is used to control the shoot through operation's duty ratio and the sine wave signal acts as a modulating signal to control the modulation index of the inverting operation. The PWM scheme for generation gate signals is shown in Fig. 6 and the circuit diagram for getting the required switching pattern is given in Fig. 7

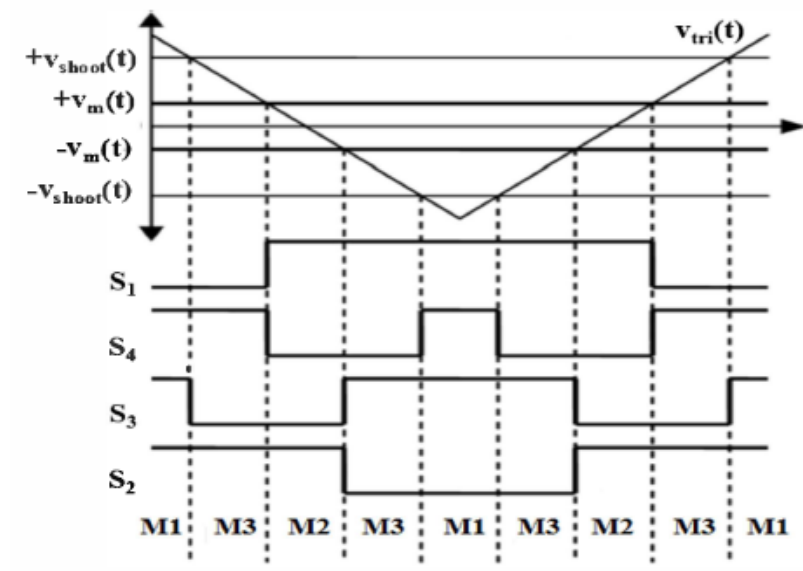

Fig 6: Desired PWM signal for generation of gate signals 


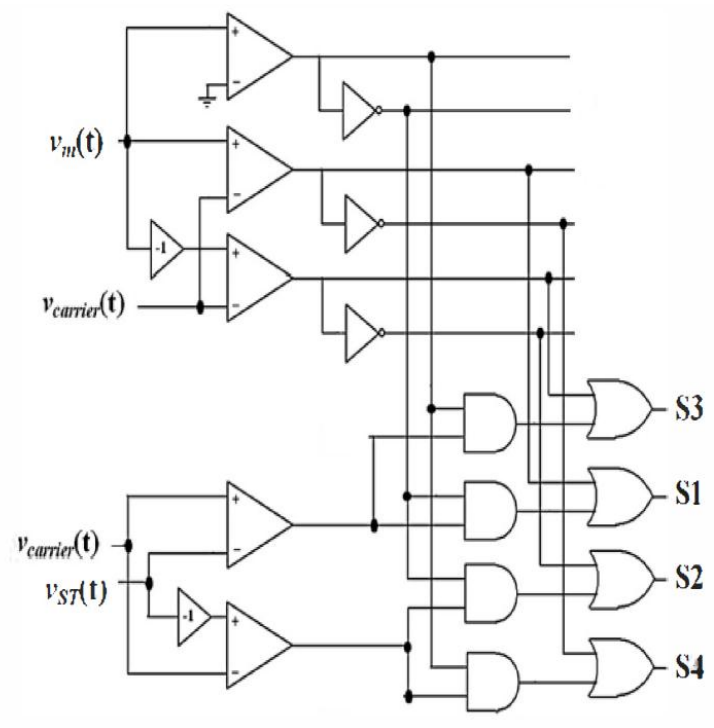

Fig 7: Circuit for implementing the PWM scheme

\section{Simulation and Results}

Table 1: Converter Parameters

\begin{tabular}{|l|l|}
\hline \multicolumn{2}{|c|}{ Table 1: Converter Parameters } \\
\hline Parameters & Attributes \\
\hline Vdcin & $12 \mathrm{~V}$ \\
\hline Vdcout & $310 \mathrm{~V}$ \\
\hline Vacout & $20 \mathrm{Vpp}$ \\
\hline DC Load Resistance & $25 \mathrm{Ohm}$ \\
\hline AC Load Resistance & $1000 \mathrm{Ohm}$ \\
\hline Switching frequency & $50 \mathrm{~Hz}$ \\
\hline Inductor L1 & $201.7 \mathrm{uH}$ \\
\hline Inductor L2 & $12.91 \mathrm{mH}$ \\
\hline Capacitor C2 & $10 \mathrm{mF}$ \\
\hline Capacitor Cac & $1 \mathrm{~F}$ \\
\hline Inductor Lac1 & $500 \mathrm{uH}$ \\
\hline Inductor Lac2 & $500 \mathrm{uH}$ \\
\hline
\end{tabular}

In the simulation the ac output is given to an ideal transformer to magnify the AC output voltage up to 325.22 Volts (this is the voltage value obtained from ac mains). The AC output value shown in the figures below is taken from the secondary side of the transformer.
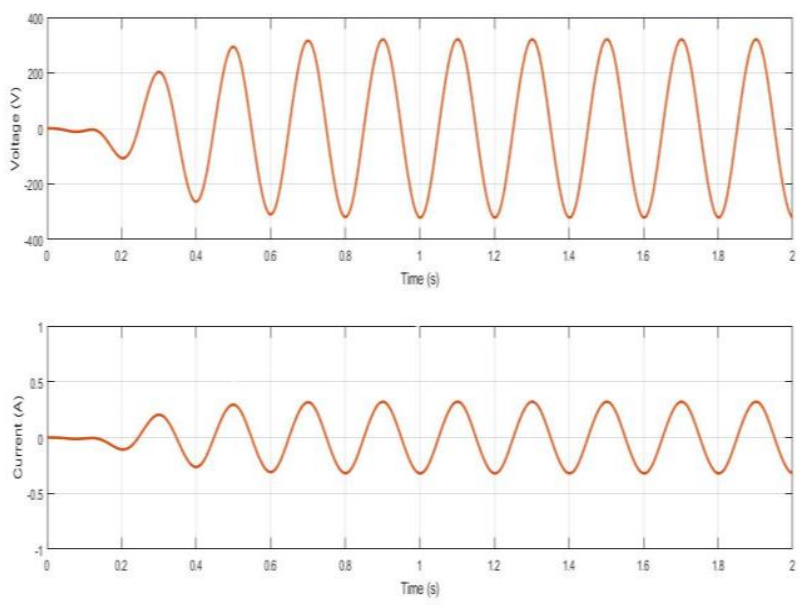

Fig 8: AC Output Voltage and Current, Dst=74\%
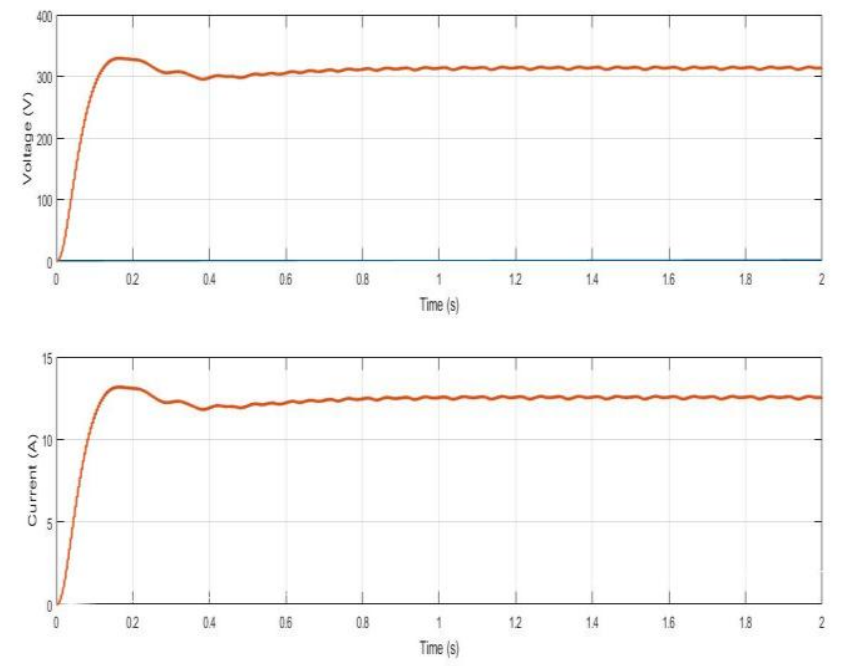

Fig 9: DC Output Voltage and Current, Dst=74\%
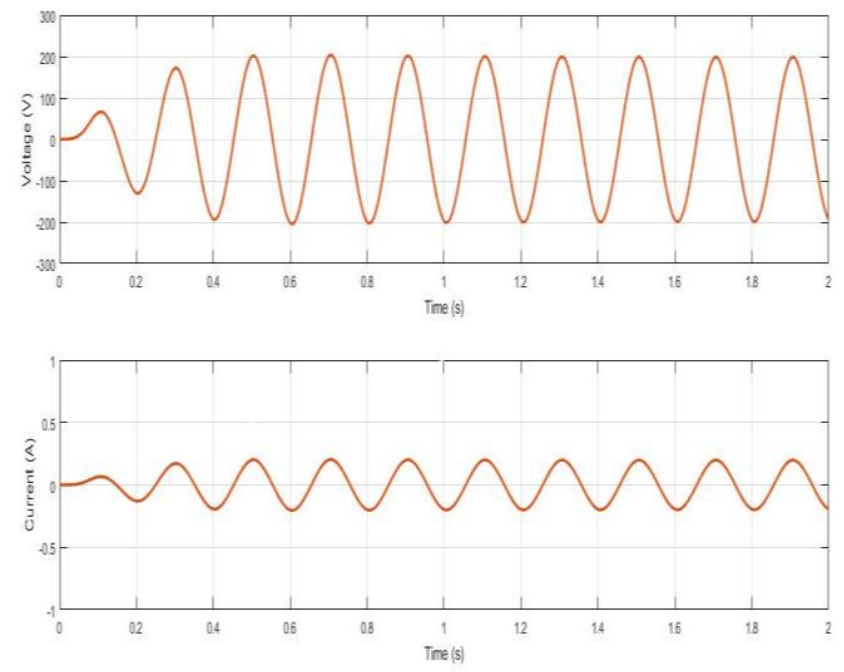

Fig 10: AC Output Voltage and Current, Dst $=65 \%$
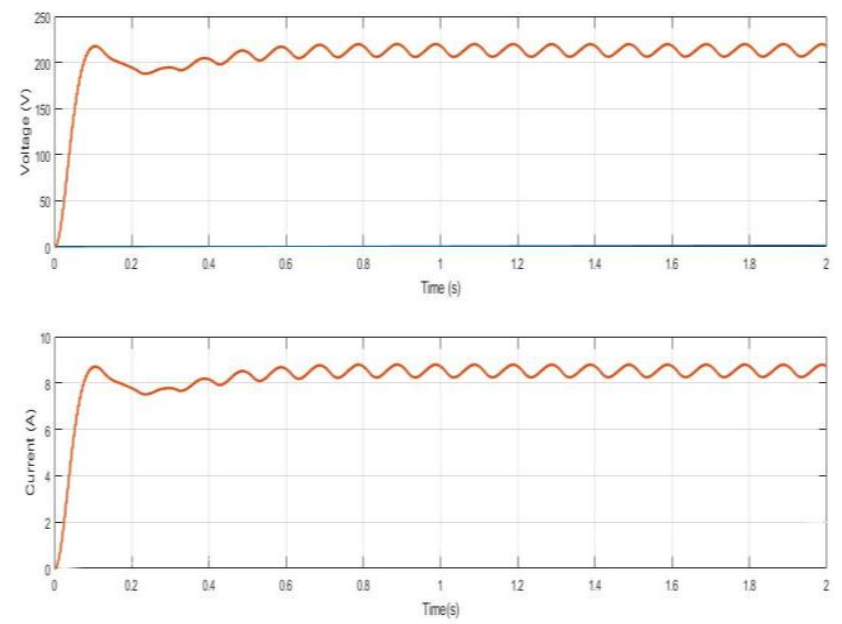

Fig 11: DC Output Voltage and Current, Dst=65\% 

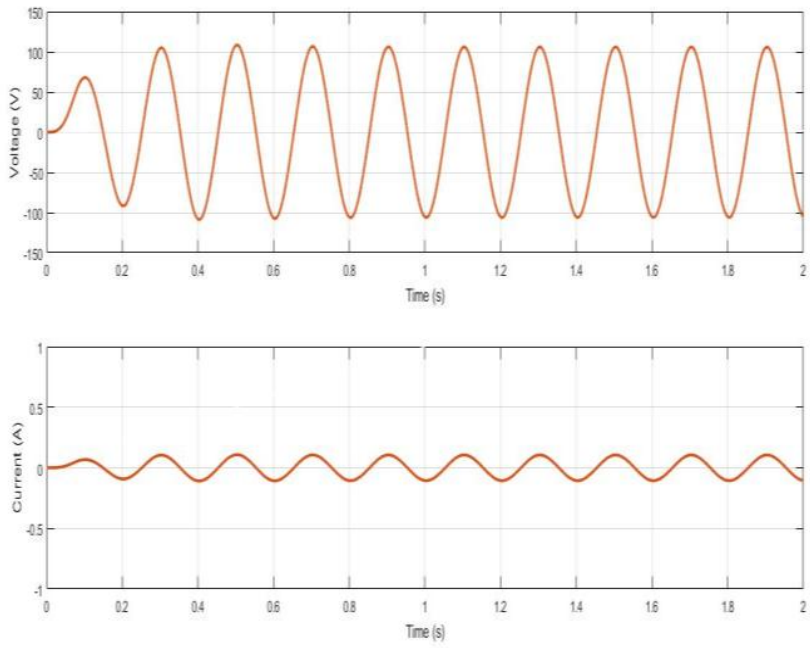

Fig 12: AC Output Voltage and Current, Dst=55\%
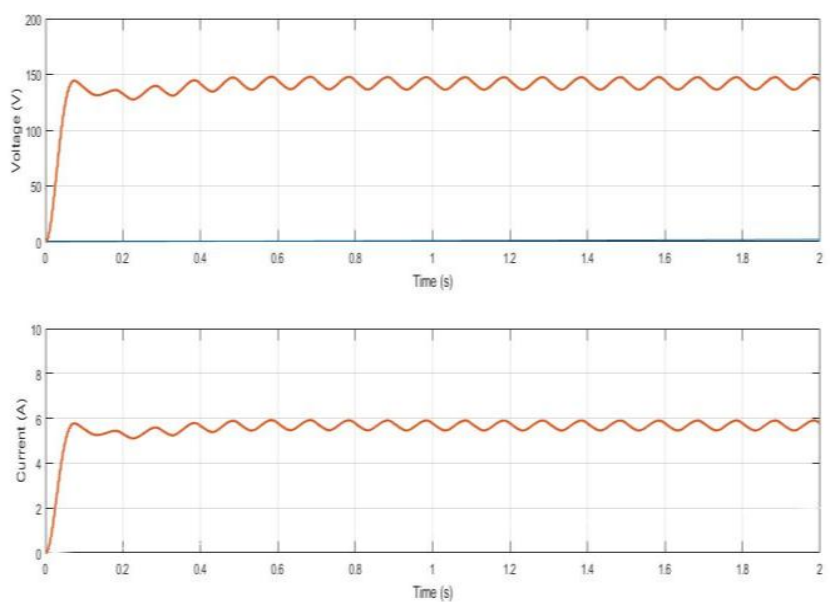

Fig 13: DC Output Voltage and Current, Dst $=55 \%$

From the simulation we have found that by varying the Vcarrier(t) signal and the Vst(t) signal we can adjust the DC output value as well as the AC output value. By increasing Vst $(\mathrm{t})$ value we can decrease DC and AC output and by decreasing it we can increase the $\mathrm{DC}$ and $\mathrm{AC}$ output value. While changing the $\mathrm{Vst}(\mathrm{t})$ values it was noted that the time taken for AC output to get stabilized gets affected. By changing the amplitude of $\operatorname{Vcarrier}(\mathrm{t})$ we can adjust the AC and DC output magnitude. High Vcarrier(t) amplitude values will give higher $\mathrm{AC}$ and $\mathrm{DC}$ outputs and vice versa.

Changing of DC and AC outputs is a bit complex as all the input PWM signal changes will affect the outputs. Proper variation must be done to get the desired output. Frequency of the input signals is also a big factor because it determines the frequency of the AC output wave. For high Dst we get higher AC and DC outputs and for low Dst we get lower AC and DC outputs.

By giving a duty ration of $74 \%$ we can observe that we get an $\mathrm{AC}$ output of 325 Volts and DC output of 310 Volts which is shown in Fig 8 and Fig 9. After this when the duty ratio was reduced to $65 \%$ there was a decrease in both the outputs but the time taken for both the outputs to stabilize has become less. Before it took at least 3 cycles for proper stabilization but now it only took two cycles for stabilization which is shown in Fig 10 and Fig 11. Obtained AC output was 20 Volts and DC output was 210 Volts. Finally the simulation was run for a duty cycle of $55 \%$ and the AC output obtained was around 110 Volts and the DC output was 145
Volts. For this simulation it took only one cycle for the AC and DC output to reach stabilization point as shown in Fig 12 and Fig 13. From this we can infer that lower duty ratios increase give faster stabilization and lower outputs and higher duty ratio gives slower stabilization but bigger outputs.

\section{Conclusion}

This paper proposes a tapped boost converter which has been hybridized to give both AC and DC outputs. Steady State Analysis of the mentioned converter has been considered to depict the characteristics at operating intervals. This converter has lots of advantages compared to the normal converters because it has shoot through protection as well as controlling of DC and AC output voltage can be easily done. Open loop simulation of the converter has been done to show authenticity of the converter.

\section{References}

[1] P. Kanakasabapathy, Sarath R, "Switched Capacitor/ SwitchedInductor Cuk Hybrid Converter for nanogrid Applications", 2015 International conference on computation of Power, Energy, Information and Communication.

[2] P. Kanakasabapathy, Sarath R, "Hybrid Converter Based on Cuk Topology to Supply Both AC and DC Loads", 2015 IEEE International Conference on Technological Advancements in Power \& Energy

[3] P. Kanakasabapathy, Kalyani Venugopal, "Multiport interleaved converter for DC microgrid applications", 2017 Innovations in Power and Advanced Computing Technologies (i-PACT)

[4] P. Kanakasabapathy, Savitha K.P, "Multi-Port DC-DC Coverter for DC Microgrid Applications",2016 IEEE 6th International conference on Power Systems, ICPS

[5] Md Junayed Sarker ,B. Asare-Bediako, J.G Slootweg W. L. Kling B. Alipuria "DC Micro-Grid with Distributed Generation for Rural Electrification" 978-1-4799-6735-3/15 2015 IEEE

[6] H. Tao, A. Kotsopoulos, J.L. Duarte and M.A.M. Hendrix “Family of multiport bidirectional DC- DC converters" IEE Proc.-Electr. Power Appl., Vol. 153, No. 3, May 2006

[7] JianwuZeng, WeiQiao, and Liyan Qu, "An Isolated Three-Port Bidirectional Converter for Photovoltaic Systems With Energy Storage" IEEE transactions on industry applications, vol. 51, no. 4, July / August 2015

[8] Hongyu Zhu, Donglai Zhang, Hussain S. Athab, BinWu, and Yu $\mathrm{Gu}$ "PV Isolated Three- Port Converter and Energy-Balancing Control Method for PV-Battery Power Supply Applications" IEEE Transactions on Industrial Eelectronics, vol. 62, no. 6, June 2015

[9] Fernando Lessa Tofoli, Denis de Castro Pereira, Wesley Josias de Paula, Demercil de Sousa Oliveira Junior, "Survey on non-isolated high-voltage step-up dc-dc topologies based on the boost converter”. IET Power Electron, 2015, Vol. 8, Iss. 10, pp. 2044-2057, The Institution of Engineering and Technology.

[10] Grant, D.A., Darroman, Y.: "Extending the tapped-inductor DC-toDC converter family", Electron. Lett., 2001, 37, pp. 145-146.

[11] Grant, D.A., Darroman, Y., Suter, J.: "Synthesis of tapped-inductor switched-mode converters", IEEE Trans. Power Electron., 2007, 22, pp.1964-1969

[12] F. Blaabjerg, Z. Chen, and S. B. Kjaer, "Power electronics as efficientinterface in dispersed power generation systems," IEEE Trans. Power Electron., vol. 19, no. 5, pp. 1184-1194, Sep. 2004.

[13] D. Boroyevich, 1. Cvefkovic, D. Dong, R. Burgos, F. Wang, and F. Lee,"Future electronic power distribution systems-A contemplative view," in Proc. 12th Int. Conf OPTIM Elect. Electron. Equip., Brasov, Romania, May 20-22, 2010, pp. 1369-1380.

[14] Zhang Hai Shi, Ka Wai Eric Cheng, Siu Lau Ho "Static performance and parasitic analysis of tapped-inductor converters." IET Power Electron, 2014, Vol. 7, Iss. 2, pp. 366-375 doi: 10.1049/ietpel. 2012.0760

[15] Olive Ray and Santanu Mishra, "Boost-Derived Hybrid Converter With Simultaneous DC and AC Outputs" IEEE Transactions on industry applications, vol. 50, no. 2, March/April 2014

[16] Michael Njoroge Gitau, Fredrick Mukundi Mwaniki and Ivan W. Hofsajer "Analysis and Design of a Single-Phase TappedCoupledInductor Boost DC-DC Converter" Journal of Power Electronics, Vol. 13, No. 4, July 2013 
[17] F. Z. Peng, "Z-source inverter," IEEE Trans. Ind. Appl., vol. 39, no. 2,pp. 504-510, Mar'/Apr. 2003.

[18] S. Upadhyay, R. Adda, S. Mishra, and A. Joshi, "Derivation and characterization of switched-boost inverter," in Proc. 14th Eur. Conf Power Electron. Appl.-EPE, Birmingham, U.K., Aug. 2011, pp. 1-10.

[19] R. Tymerski and v. Vorperian, "Generation, classification and analysis of switched-mode dc-to-dc converters by the use of switched inductor cells,"in Proc. Int. Telecommun. Energy Conj:, Oct. 1986, pp. 181-195.

[20] O. Ray and S. Mishra, "Boost-derived hybrid converter with simultaneous DC and AC outputs," in iEEE Tr.ws. on industlY Appl., vol.50, no. 2, pp. 1082-1093, Mar.-Apr. 2014.

[21] R. Adda, S. Mishra, and A. Joshi, "A PWM control strategy for switched boost inverter," in Proc. IEEE ECCE, Phoenix, AZ, USA, Sep.2011, pp. 991-996.

[22] S. H. Hwang and J. M. Kim, "Dead time compensation method for voltage-fed PWM inverter," IEEE Trans. Energy Convers., vol. 25, no.1, pp. 1-10, Mar. 2010.

[23] R. W. Erickson and D. Maksimovic, Fundamentals of Power Electronics, 2nd ed. New York, NY, USA: Springer-Verlag, 2001. 